\title{
IDENTIDADE E EXCLUSÃO: O POVO GUARANI DE MATO GROSSO DO SUL
}

\author{
IDENTITY AND EXCLUSION: THE GUARANI PEOPLE FROM MATO GROSSO DO SUL
}

\author{
Vania Maria Lescano Guerra \\ Universidade Federal de Mato Grosso do Sul \\ Juliana Marques de Matos Amorim \\ Universidade Federal de Mato Grosso do Sul
}

\begin{abstract}
RESUMO: A proposta desta pesquisa é problematizar os discursos midiáticos sobre a desnutrição nas aldeias indígenas de Dourados-MS, de forma a obter as representações do indígena sul-mato-grossense construídas pelo discurso da mídia. Para tanto, como corpus da pesquisa temos os discursos do jornal Folha On-Line, jornal digital de circulação nacional. A busca por esse objetivo resultou neste trabalho, no qual se aborda o tema sob a ótica da Análise do Discurso de origem francesa, ancorando-se em obras de teóricos como Orlandi (2007), Coracini (2007) e Authier-Revuz (1990); e em estudiosos de cultura e identidade - sendo os principais Bhabha (1998), Castells (1999), Foucault (1990; 1996) e Souza (2003). Desestabilizamos os discursos midiáticos sobre o índio guarani mediante o estudo de sua atuação na História, de forma que possa haver compreensão sobre seu papel na sociedade atual e sobre sua representação no imaginário popular.
\end{abstract}

PALAVRAS-CHAVE: mídia; representação; discurso; índio.

ABSTRACT: The purpose of this research is to question the media discourse about malnutrition in the indigenous villages of Dourados - MS, to obtain the representations of indigenous of Mato Grosso do Sul built by media discourse. For this, as we have research corpus speeches Folha On-line, digital newspaper of national circulation. The pursuit of this goal has resulted in this work, which addresses the issue from the perspective of French Discourse Analysis, in the basis of the works of theorists like Orlandi (2007), Coracini (2007) and Authier-Revuz (1990); and theorists of culture end identity - being the main Bhabha (1998), Foucault (1990; 1996), Castells (1999) and Souza (2003). We destabilize the media discourse about the Guarani Indian by studying its role in History, so you can be understanding about their role in modern society and about their representation in the popular imagination.

KEYWORDS: media; representation; discourse; indian

\section{Palavras iniciais}

A situação de desnutrição nas aldeias de Dourados - MS descrita nas páginas de jornais brasileiros do ano de 2005, era comumente denominada como uma "tragédia", "fatalidade", ou mesmo consequência de uma possível falta de responsabilidade por parte das autoridades competentes. Tal situação nos leva à tentativa de entendê-la pelo viés discursivo, pois, dessas reportagens, não sobressaíam somente efeitos de sentido por 


\section{Revista do SELL \\ v. $4, n^{\circ} .1$}

ISSN: $1983-3873$

parte do discurso do jornal, mas também a (re)construção da imagem do índio perante a sociedade - já que esta tende a adotar como verdades inquestionáveis o que é exposto na mídia, vista como uma instituição que inspira credibilidade. Dessa forma, trabalha no inconsciente do público de modo que deixe vivas determinadas memórias discursivas (CORACINI, 2007) que são mantidas no público mediante a repetição, que assegura sua condição de construtoras de estereótipos e representações (BHABHA, 1998).

No ano de 2005, o discurso corrente nos jornais locais e mesmo em alguns periódicos nacionais sobre a situação da reserva indígena de Dourados trazia frequentemente termos como "tragédia", "desnutrição", "abandono", "miséria", que, naquele momento, serviam para descrever a calamidade; porém, em determinadas condições, tais palavras poderiam servir não apenas como elementos descritivos dos acontecimentos em curso, mas também para invocar a atenção e a emoção do público diante de certas notícias - uma vez que o interesse do leitor/espectador é guiado por extremos (CHARAUDEAU, 2009). Captado o interesse do público, formam-se em seu imaginário as representações daqueles que ali são retratados como inferiores e entraves para a sociedade envolvente, forma como são mostrados pela mídia. Matérias que focalizam sua cultura ou suas palavras ocupam bem menos espaço do que aquelas que registram sua miséria.

O jornal selecionado para este estudo é referência de notícias, pois atinge determinado público, contribuindo para a formação de opinião do leitor, de modo que o estudo aqui proposto, por questionar estratégias discursivas e potenciais efeitos de sentido junto ao público, poderá suscitar reflexões sobre a construção de imagens veiculadas pelas notícias. Acredita-se que este trabalho possa contribuir para uma leitura mais reflexiva ao mostrar que o texto jornalístico requer um leitor atento a reconhecer na materialidade discursiva as pistas dos processos de significação.

Sob a concepção foucaultiana de arqueologia - em que articulamos dados históricos no processo de desconstrução discursiva -, trazemos para a análise dados históricos, fundamentados especialmente na obra de Aylwin (2009) e de Ramos (1988). Como bases para a análise linguística, Silva (2007) oferece relevantes esclarecimentos sobre os processos de referenciação na perspectiva discursiva, assim como Neves (2000), Fiorin (1996) e Flores, et al (2008) contribuem para a análise dos demais aspectos da materialidade linguística dos discursos. $\mathrm{Na}$ análise de excertos do jornal, identificam-se 


\section{Revista do SELL}

v. $4, n^{\circ} .1$

ISSN: $1983-3873$

as regularidades que os caracterizam como propagadores de representações perante 0 público leitor, de forma a trazer os resultados provenientes da pesquisa, assim como uma breve discussão sobre esses resultados.

\section{Folha On-line: a repercussão da desnutrição indígena no país}

Dentre os variados assuntos abordados pela agenda-setting da Folha On-line, os casos de desnutrição infantil entre os índios guaranis de Dourados fizeram parte de sua pauta, fazendo que o assunto se tornasse parte integrante também dos interesses do público de todo o país. Neste item, os excertos extraídos da Folha On-line seguem a sua numeração própria, antecedidos da inicial do nome do jornal, com o intuito de propiciar maior destaque aos enunciados. O primeiro excerto a ser analisado - "Cresce mortalidade infantil indígena", do dia 25 de janeiro de 2005 - refere-se ao aumento da mortalidade infantil nas aldeias de Dourados e de possíveis causas para a desnutrição das crianças indígenas:

F1 - A desnutrição e mortalidade infantil estão relacionadas à falta de terra e os casos de alcoolismo entre os índios, afirmou o coordenador-regional da Funasa, Gaspar Hickman.

"Os pais bebem e abandonam os filhos em casa. As crianças ficam até três dias sem comer", afirma a nutricionista Cíntia Naito que coordenada [sic] o programa de vigilância nutricional nas aldeias.

No enunciado "A desnutrição e mortalidade infantil", o artigo definido em destaque aponta os casos de desnutrição como específicos, e não como fatos isolados, e traz, portanto, "uma informação conhecida tanto do falante quanto do ouvinte" (NEVES, 2000, p. 391). A autora afirma ainda que o artigo tem sua ocorrência efetivada em sintagmas referenciais, exercendo, no caso do enunciado em análise, a função de referência indireta, por depender "exclusivamente do conhecimento compartilhado entre falante e ouvinte, e os interlocutores sabem a que entidade se faz referência" (NEVES, 2010, p. 391). Também Roncarati (2010, p. 59) afirma que o uso do artigo definido pode ser classificado ainda como uma forma de expressão referencial com descrição definida, por fazer remissão a elementos que estão fora do momento do enunciado. Assim, quando se menciona "A desnutrição", os leitores já a associam às diversas ocorrências anteriores, cuja característica de constância e progressão é ainda confirmada pelo título da reportagem, "Cresce mortalidade infantil indígena". 


\section{Revista do SELL}

v. $4, n^{\circ} .1$

ISSN: $1983-3873$

Após essa leitura inicial, cabe uma reflexão sobre os investimentos semânticos realizados nessa reportagem. Para Miqueletti (2007), os temas principais dos jornais no ano de 2005 foram: a falta de condições de sobrevivência na Reserva de Dourados e a forma de vida desses sujeitos: esses dizeres são permeados pelas figuras representadas pelas famílias vítimas do descaso, pela descrição do local em que vivem. Segundo a autora, nesse contexto, a ênfase dada pelos jornais locais, no que se refere à descrição do espaço aldeia, informa sobre as casas e sobre o modo de vida na Reserva, o que possibilita mais veracidade ao que é contado e ajuda a compor esse Outro, o indígena, que é visto pelas lentes desse Eu, o branco. Destaca-se que os discursos desempenham funções sociais no contexto em que atuam e a mídia exerce papel considerável na sua divulgação, os discursos fundem-se e se expandem guiados pelos suportes que os veiculam. Ressaltamos aqui que o suporte jornal escrito, no intuito da responsabilidade de "informar", veicula também valores, ideologias próprias de determinado contexto de enunciação, de certa formação ideológica na qual o discurso encontra-se inserido.

Diante disso, articulamos, na materialidade da língua, o uso que o jornalista faz da conjunção coordenativa "e", em "A desnutrição e mortalidade infantil": segundo Perini (2010, p. 160), a coordenação, juntamente com a subordinação, compõe a dupla de processos básicos que juntam unidades de uma mesma classe para se formar uma classe maior; dessa forma, a coordenação não ocorre apenas no nível de composição de um enunciado, mas também na coordenação de sintagmas nominais, como no excerto analisado. Neves $(2000$, p. 739$)$ ressalta que a conjunção "e" "marca uma relação de adição entre os segmentos coordenados", de forma que, no caso do enunciado em análise, os segmentos "desnutrição" e "mortalidade" estão estreitamente relacionados, e tal relação é demonstrada pelo uso da conjunção coordenativa. Observa-se que, ao invés de especificar cada palavra por meio de artigo (A desnutrição e a mortalidade), 0 enunciado do jornalista estabelece uma relação de sinonímia entre elas, ao publicar como "A desnutrição e mortalidade" - passando ao leitor o efeito de sentido de que ambas são indissociáveis.

Em "A desnutrição e mortalidade infantil estão relacionadas à falta de terra e os casos de alcoolismo entre os índios", também há a ocorrência de artigos definidos (no caso de "à falta de terra", o artigo está junto a uma preposição, em uma fusão denominada crase) fazendo referência exofórica: ambos os "fenômenos" estão relacionados a fatores exteriores ao enunciado - os conflitos decorrentes da falta de terra 


\section{Revista do SELL}

v. $4, n^{\circ} .1$

ISSN: $1983-3873$

e o alcoolismo relacionado aos índios eram, e são, constantes na grade de notícias dos jornais, o que justifica a constante remissão a estes dados referenciais. $O$ fato de tais dados - alcoolismo, falta de terra, desnutrição - serem constantemente referenciados nos jornais alude à "fixidez na construção ideológica da alteridade", mencionada por Bhabha (1998, p. 105). Segundo o autor, quando há constante repetição de dados referentes a uma determinada classe, etnia ou gênero, existe o desejo de manter certos estereótipos, com o objetivo de manter o poder de outras camadas da sociedade. Ou seja, ao serem referenciados com frequência na condição de "alcoólatras", "sem terras" e "desnutridos", tal repetição os deixa permanentemente nessas condições, garantindo que permaneçam (pelo menos em termos de memória) os mesmos em todos os processos de evolução da História e do discurso, produzindo efeitos de verdade e reforçando a imagem dos demais como "superiores".

Em "A desnutrição e mortalidade infantil estão relacionadas à falta de terra e os casos de alcoolismo entre os índios, afirmou o coordenador-regional da FUNASA, Gaspar Hickman", o verbo em destaque caracteriza o enunciado que o precede como um discurso indireto; porém o verbo não introduz o enunciado, mas sim o encerra, o que provoca um efeito de sentido de que o discurso do coordenador se funde ao discurso do jornal - se, por exemplo, tivéssemos o enunciado "O coordenador-regional da FUNASA Gaspar Hickman afirmou que a desnutrição e a mortalidade estão relacionadas à falta de terra e os casos de alcoolismo entre os índios", a introdução da fala do coordenador pelo verbo revelaria um grau de adesão maior deste em relação a esse discurso. Com relação ao tempo verbal empregado em "afirmou", trata-se do pretérito perfeito, que designa uma ação como "algo acabado, como uma descontinuidade (um ponto) na continuidade do momento de referência e, portanto, como algo dinâmico, visto do exterior" (FIORIN, 1996, p. 155); quanto a seu significado, o verbo é sinônimo de "declarar com firmeza", "asseverar", "consolidar" (AMORA, 2003, p. 19), de modo que traz para o enunciado um efeito de verdade, uma vez que consolida uma posição de certeza por parte do enunciador. O uso desse verbo também designa o lugar de onde se fala (FOUCAULT, 1996, p. 9); seu valor de verdade provém do fato de que foi proferido por alguém cujo poder é institucionalizado - segundo Foucault (1996, p. 17), a "vontade de verdade" de um discurso (e seu poder) apoia-se sempre sobre um suporte institucional. $O$ verbo "afirmar" é usado também para consolidar a fala da nutricionista, quando esta enumera os motivos pelos quais as crianças morrem por desnutrição. 


\section{Revista do SELL}

v. $4, n^{\circ} .1$

ISSN: $1983-3873$

A respeito da fala da nutricionista, sua forma de inscrição no discurso do jornal é por meio do uso de aspas, caracterizando a forma de heterogeneidade mostrada de forma marcada ou explícita (CHARAUDEAU; MAINGUENEAU, 2004, p. 261); trata-se da representação de um discurso diverso dentro do discurso de outro, da inserção de um "exterior específico" de forma a operar certa "constituição de identidade" para o discurso (AUTHIER-REVUZ, 1990, p. 31). O discurso da nutricionista inserido no discurso jornalístico confere a este uma identificação com uma formação discursiva médica, carregando em si considerações médicas a respeito do problema em questão.

Em "Os pais bebem e abandonam os filhos em casa. As crianças ficam até três dias sem comer", os artigos definidos em destaque desempenham o papel de referência indireta (NEVES, 2000, p. 391), pois dependem exclusivamente de um saber compartilhado entre o leitor e o jornalista. Alguém que lesse tal enunciado de forma isolada e não tivesse conhecimento da situação das aldeias indígenas não compreenderia a quais crianças e a quais pais o jornalista se refere. Quando se apresenta tal forma de referência, "os interlocutores sabem a que entidade se faz referência" (NEVES, 2000, p. 391), mesmo que esta não esteja presente na situação de enunciação. Os artigos também especificam os sujeitos envolvidos na situação descrita: são "os pais" que abandonam as crianças, e não outra pessoa qualquer; nesse enunciado, há a responsabilização dos pais pela situação da saúde dos filhos, como se o sistema de saúde e os governantes não tivessem responsabilidade alguma com o fato.

Mesmo tendo a propriedade de particularizar um indivíduo, o artigo pode também generalizá-lo, quando utilizado em referências (NEVES, 2000, p. 395). A associação entre os vocábulos "pais", "filhos" e "crianças", introduzidos pelos artigos definidos, constitui-se ainda em formas de anáfora associativa, pois um remete à presença do outro. Isso remete também ao efeito de sentido de que os pais são os responsáveis pela desnutrição dos filhos, e não o sistema de saúde inadequado, ou as falhas na distribuição de cestas básicas (conforme está exposto em F2). Em F1, destacamos também a preposição "até", em "As crianças ficam até três dias sem comer". No enunciado, a preposição introduz o sentido de "ação que atinge o limite temporal" e faz referência a outros conjuntos de ações e atitudes (falta de terra, casos de alcoolismo) que estão envolvidos nesse limite de tempo (FLORES, et al., 2008, p. 138), e que culminam nos fatores "desnutrição" e "mortalidade". 


\section{Revista do SELL}

v. $4, n^{\circ} .1$

ISSN: $1983-3873$

O discurso do coordenador regional da FUNASA, Gaspar Hickmann, reforça a ideia de que a responsabilidade pelos casos de desnutrição está sendo atribuída aos próprios índios, ao mesmo tempo em que isenta de culpa a instituição em que atua. Esse discurso ganha efeito de verdade em virtude de sua origem, que é institucional (FOUCAULT, 1996, p. 17), o que faz que obtenha um poder de coerção, que "pressiona" a produção de outros discursos com conteúdo semelhante. Ressaltamos que o discurso da nutricionista (proveniente de uma formação discursiva médica), ao dizer que "os pais bebem e abandonam os filhos em casa", é praticamente um "embasamento científico" do discurso do coordenador regional, que mencionara o alcoolismo nas aldeias como um dos motivos por haver crianças morrendo de desnutrição. Assim, tal discurso ganha força pela sua transmissão de um sujeito a outro, e deste para outros sujeitos. (FOUCAULT, 1990, p.101).

Cabe ressaltar que nas narrativas sobre a desnutrição indígena, divulgadas no ano de 2004, não se verifica a divulgação de um caso específico de morte, alguns são apenas lembrados e, na maioria das vezes, trata-se da situação como um todo, ou melhor, de casos já ocorridos, ou que estão na eminência de acontecer devido às más condições de vida. Nesses termos, verifica-se que a instauração dos elementos da enunciação ocorre de acordo com escolhas realizadas pelo enunciador tendo em vista a construção de determinado sentido que vai sendo configurado também nas escolhas das vozes requeridas para o texto. Assim, a partir do ano de 2005, as discursividades vão sendo construídas, parafraseadas, na direção de argumentar que desnutrição e morte estão associadas.

Nessa direção, trazemos o próximo excerto a ser problematizado, cuja reportagem intitula-se "Índia de 3 anos morre de desnutrição", publicada em 9 de fevereiro de 2005, e argumenta a respeito de algumas estatísticas sobre a mortalidade infantil nas aldeias, para comentar as circunstâncias da morte da criança:

F2 - O médico Antônio Aurélio Teixeira de Carvalho Neto disse que o caso da criança morta ontem pode ser mais grave ainda, pois os pais da menina não deixavam a equipe de saúde da Funasa tratar da criança desnutrida.

"Eu mesmo fui expulso da casa pelo pai. Foi em dezembro. Às vezes, os índios pensam que a gente quer tomar a criança. Só uma 


\section{Revista do SELL \\ v. $4, n^{\circ} .1$ \\ ISSN: $1983-3873$}

necropsia para saber o que exatamente causou a morte da criança", afirmou Neto.

A uma emissora de rádio de Dourados, o índio Sebastião Isnarde, 24, pai da criança, disse ontem que a filha passava fome, pois a família não recebia cestas de alimento do estado.

Nesse enunciado, as formas verbais "afirmou" e "disse", ambas no pretérito perfeito, segundo Fiorin (1996, p. 152), tais formas marcam "uma relação de anterioridade entre o momento do acontecimento" (quando o médico proferiu o discurso) "e o momento de referência presente" (quando o discurso do médico foi reproduzido pelo jornal). Para Corôa (2005, p. 48), verbos no pretérito refletem o mundo com mais objetividade, uma vez que são usados para "relatar eventos, estados ou processos já acontecidos" e, portanto, interpretados como mais próximos à realidade. Segundo a autora, tais verbos estão ligados intrinsecamente ao momento do evento - no caso, o momento em que o médico "foi expulso" e o momento da agonia da criança passando fome (a qual foi relatada pelo pai a uma emissora de rádio). "É nos tempora do pretérito que o momento do evento está mais bem delimitado e localizado: ocorre sempre antes do momento da fala" (CORÔA, 2005, p. 48-49).

Ressaltamos ainda a seguinte afirmativa do médico: "o caso da criança morta ontem pode ser mais grave ainda, pois os pais da menina não deixavam a equipe de saúde da FUNASA tratar da criança desnutrida". O advérbio de intensidade "mais" e o advérbio de tempo "ainda", intercalados pelo adjetivo "grave", enfatizam que a omissão dos pais em relação ao tratamento da criança é mais condenável do que a própria suposição de que a criança teria morrido de fome - fato esse que seria confirmado posteriormente pelo pai da mesma, ao afirmar que a família não recebia as cestas de alimento que Ihes eram de direito. Segundo Neves (2000, p, 236), o advérbio "mais" exerce uma função modificadora, pois afeta "o significado do elemento" sobre o qual incide (no caso aqui, a morte da criança) fazendo uma predicação sobre as propriedades desses elementos: "ser mais grave ainda". O advérbio "ainda" contribui para acentuar o valor de verdade do enunciado, trazendo para o leitor o efeito de sentido de que o caso seria "mais grave" do que se acreditava e mesmo "mais grave" do que outros que já haviam sido noticiados pelo jornal.

O discurso do médico, inscrito no discurso do jornal como heterogeneidade mostrada em forma marcada por meio de aspas (AUTHIER-REVUZ, 1990, p. 33; 


\section{Revista do SELL \\ v. $4, n^{\circ} .1$}

ISSN: $1983-3873$

CHARAUDEAU; MAINGUENEAU, 2004, p. 261), apresenta-se com valor de verdade. Em uma de suas afirmativas, diz ter "ele mesmo" sido expulso da casa dos pais da criança, no sentido de afirmar que "de fato" houvera sido expulso: o vocábulo "mesmo", segundo Amora (2003, p. 459), significa "de fato", "realmente", e expressa a indignação do médico sobre o fato - indignação que é confirmada na afirmativa seguinte, quando o médico diz que "Só uma necropsia para saber o que exatamente causou a morte da criança" - ou seja, se enquanto estava viva os pais não permitiram o acesso do médico à criança, só com sua morte seria possível saber sobre seu estado de saúde. Nesse enunciado, podemos identificar também a "quebra" do discurso institucionalizado do médico: apesar de ter o suporte de uma instituição (a FUNASA) para exercer sua autoridade como profissional da saúde, Antônio Aurélio Teixeira de Carvalho Neto foi expulso da casa pelo pai da criança, o que se poderia classificar como uma forma de resistência. Segundo Foucault (1990, p. 95), "onde há poder, há resistência"; pela perspectiva do autor, não há como dissociar resistência e poder.

A existência do poder depende em grande parte da multiplicidade de resistências, que o colocam constantemente à prova; porém as formas de resistência são mobilizadas de maneira irregular - embora definitiva -, agindo somente em determinadas situações, e não de forma regularizada, como o poder: "the points, knots, or focuses of resistance are spread over time and space at varying densities, at times mobilizing groups or individuals in a definitive way, inflaming certain points of the body, certain moments in life, certain types of behavior"1 (FOUCAULT, 1990, p. 96). Assim, embora haja resistências por parte do índio, elas ocorrem em focos isolados, às vezes individualmente (como no caso do pai que expulsou o médico), às vezes em forma de mobilização de grupos, mas não de modo constante e permanente, como as formas de poder.

No enunciado "Às vezes, os índios pensam que a gente quer tomar a criança", o termo em destaque referencia, ao mesmo tempo, o índio que proibiu a entrada do médico para examinar a criança, e outros índios de uma forma geral; ao mesmo tempo em que se constitui como uma anáfora direta, por referenciar o pai da criança, já citado no enunciado, também pode ter o efeito de sentido de uma anáfora indireta, pois remete a outros índios que não o citado na reportagem. (SILVA, 2007, p. 197). Além de generalizar

\footnotetext{
1 "Os pontos, nós, ou focos de resistência estão espalhados ao longo do tempo e do espaço em densidades diferentes, às vezes mobilizando grupos ou indivíduos de maneira definitiva, inflamando certos pontos do corpo, certos momentos da vida, certos tipos de comportamento". (FOUCAULT, 1990, p. 96)
} 


\section{Revista do SELL \\ v. $4, n^{\circ} .1$}

ISSN: $1983-3873$

um conceito sobre os índios guaranis, o termo destacado ainda traz à tona o efeito de sentido de que somente os índios impedem o tratamento médico para suas crianças; ou de que somente eles poderiam pensar que o médico "tomaria" seus filhos. No caso do impedimento da assistência médica pelos pais, salientamos o aspecto cultural que possa estar envolvido nessa situação. Apesar de estarem muito próximos da cultura da sociedade envolvente, os índios guaranis conservam fortes traços de sua cultura de origem. Segundo Brandão (1986, p. 103), esse seria um caso em que "as transformações provocadas no interior do sistema interétnico sobre as condições pré-contacto [...] não destruíram plenamente uma espécie de sentimento coletivo". Nas sociedades de entorno, poucas pessoas têm conhecimento acerca de certos costumes que permeiam, por exemplo, a alimentação dos índios, a qual é "revestida de valores culturais que podem ser objeto de grande elaboração simbólica" (RAMOS, 1988, p. 43). Há, nessa cultura, algumas "interdições alimentares", em que determinados tipos de alimentos que servem aos mais velhos não devem, em hipótese alguma, serem servidos às crianças, e viceversa - o que Ramos denomina de "tabus alimentares" (RAMOS, 1988, p. 44).

Não se sabe ao certo até que ponto tais "tabus" são respeitados na atualidade pelos guaranis, mas deve-se considerar a possibilidade de alguns pais vetarem às crianças alimentos que considerariam inapropriados conforme sua cultura- além do fato de as mencionadas "cestas de alimento do Estado" não serem corretamente distribuídas. A manutenção de alguns de seus traços culturais caracteriza-se como uma forma de resistência perante a sociedade envolvente, confirmando uma negação em assumir uma perda de identidade. Por outro lado, se o índio guarani perdeu uma parte de seus aspectos culturais, podemos afirmar que assumiu a identidade de projeto mencionada por Castells (1999), em que abre mão de grande parte de sua cultura para adequar-se à realidade das sociedades de entorno. O fato de aceitar (e necessitar de) receber cestas do governo, mesmo tendo "tabus alimentares" em sua cultura original, marca essa condição de adequação: a própria proximidade com o branco - que transformou o antes vasto território indígena em "propriedade privada" (RAMOS, 1988, p. 16), obrigando-os a vender barato sua mão de obra aos invasores - gerou essa situação de dependência de recursos.

A seguir, em matéria do dia 22 de fevereiro, o jornal Folha On-line destaca a morte de "mais uma criança índia" por desnutrição: 


\section{Revista do SELL}

v. $4, n^{\circ} .1$

ISSN: $1983-3873$

F3 - Fome mata mais uma criança índia em MS - a desnutrição causou a morte de mais uma criança índia em Dourados $(218$ km de Campo Grande, em Mato Grosso do Sul). "A desnutrição levou à diarréia e à desidratação, e a criança morreu", afirmou ontem o médico Zélik Trajber, 58, que presta serviço de assistência para a Funasa (Fundação Nacional de Saúde).

A menina K. F., que tinha seis meses e 15 dias de vida, morreu no sábado pela manhã no Hospital da Mulher localizado na cidade, mas a morte só foi confirmada ontem pela Funasa. $O$ bebê estava internado havia nove dias.

É o terceiro caso de morte por desnutrição neste ano nas aldeias de Dourados. [...]

O médico Helder Lúcio Ganacin, 33, também da Funasa, e Trajber informaram que no atestado de óbito constará como causa da morte desidratação e diarréia. Ganacin e Trajber disseram que a desnutrição tornou a criança mais vulnerável às doenças, porém não aparecerá como motivo da morte.

O jornal introduz a matéria com um verbo na voz ativa - "Fome mata mais uma criança índia em MS" -, indicando, no início, a causa direta das mortes das crianças indígenas, na utilização direta da causa (fome) no lugar da consequência (desnutrição). Ao qualificar a vítima da fome, utiliza um termo que normalmente é utilizado como substantivo (índia), em lugar de um adjetivo (indígena). Equiparar um termo com função de substantivo a outro adjetivo faz que um denomine o outro em um processo de referenciação. Segundo Neves (2000, p. 184), “isso acontece especialmente com adjetivos que, à força de ocorrer constantemente junto do mesmo substantivo, acabam por assumir o papel desse substantivo, passando a denominar o referente". Assim, o termo "criança" pode ser referenciado ao longo do enunciado como "índia" ou como "indígena". Outro termo a ser problematizado no título da matéria "Fome mata mais uma criança índia em MS" é o vocábulo "mais", que acentua a quantidade de crianças mortas por desnutrição; exprime também uma noção de anterioridade ao ocorrido, deixando claro que já morreram outras crianças além do que está descrito na matéria e lançando, consequentemente, a questão: o que (não) foi feito para impedir essas mortes? Por que elas não puderam ser evitadas?

O efeito de sentido de que a criança é apenas "mais uma" colabora, também, para uma representação de fragilidade dos indígenas, pressupondo uma cadeia de eventos 


\section{Revista do SELL}

v. $4, n^{\circ} .1$

ISSN: $1983-3873$

aos quais se vão somando outros - se houve "mais uma" morte, provavelmente haverá outras. Podemos comparar a situação de fragilidade dos indígenas à situação dos escravos na História do Brasil, baseando-nos no fato de que ambos foram explorados no processo de desenvolvimento do País e deixados à margem da sociedade que fora "construída". Nessa direção, afirmamos que, constituindo o que Souza (2003, p. 105) denominou de "periferia", os indígenas tornaram-se "homens a rigor dispensáveis, desvinculados dos processos essenciais à sociedade" (SOUZA, 2003, p. 122). Desvinculados da sociedade, seus atos e sua cultura não despertam o interesse da população que a compõe. Assim, mesmo aquele que morre em decorrência de algo tão grave quanto a fome, torna-se apenas "mais um" entre tantos outros que já morreram e que, possivelmente, ainda vão morrer. Embora Ihes sejam garantidos, pelo Estatuto do Índio (1973) e pela Constituição Federal (1988), os mesmos tratamentos de saúde oferecidos à sociedade de entorno, não ocorre que alguma comunidade dessa sociedade tenha as mesmas porcentagens de mortes infantis que a Reserva de Dourados - o que revela que o tratamento não é o mesmo². Em F3, há também a ocorrência de um numeral ordinal para referenciar um dos casos de morte por desnutrição na Reserva de Dourados: "É o terceiro caso de morte por desnutrição neste ano nas aldeias de Dourados". Segundo Neves (2000, p. 591), "os numerais ordinais indicam ordem numérica dentro de uma série", funcionando como "adjetivos classificadores com indicação de ordem numericamente definida"; ao mesmo tempo em que indica a ordem de acontecimentos, qualifica também a criança dentro dessa cadeia de eventos.

Em sua fala, o médico Zélik Trajber afirma que "A desnutrição levou à diarréia e à desidratação, e a criança morreu". Observa-se uma tentativa de "isentar" a desnutrição da morte da criança. Consta que oito óbitos foram causados por doenças relacionadas à desnutrição; em F3, ocorre o mesmo: morte por diarreia e desidratação causadas por desnutrição, o que deixa margem à estratégia de fazer constar nos registros oficiais a morte pelos sintomas, e não por sua causa direta, conferindo o efeito de sentido de diminuição de mortes por desnutrição (apesar de o fato ser descrito como "mais uma" morte por fome). O verbo "levar", em "A desnutrição levou à diarréia e à desidratação", tem, no entanto, o sentido de "aproximar", "fazer chegar", "encaminhar", "direcionar" (AMORA, 2005, p. 537), o que revela a desnutrição como a causa direta da morte.

\footnotetext{
${ }^{2}$ Por exemplo, de acordo com o Art. 54 do Estatuto do Índio, "Os índios têm direito aos meios de proteção à saúde, facultados à comunhão nacional".
} 


\section{Revista do SELL \\ v. $4, n^{\circ} .1$}

ISSN: $1983-3873$

No último parágrafo de $\mathrm{F} 3$, os médicos da FUNASA informam que "no atestado de óbito constará como causa da morte desidratação e diarréia"; o verbo "constar" equivale a "registrar" (AMORA, 2005, p. 232), que advém de uma formação discursiva jurídica, de caráter oficial, que confere efeito de verdade ao que foi afirmado. Oficialmente, para todos os efeitos jurídicos, a morte não ocorreu por desnutrição, embora os médicos admitam que essa tornasse a criança "mais vulnerável". Admitir oficial e juridicamente que crianças estão morrendo de fome não é algo edificante à imagem dos órgãos oficiais responsáveis pela saúde. Isso porque se sabe que eles podem ser responsabilizados diretamente pela morte, uma vez que o Estatuto assegura que os índios tenham o mesmo tratamento e atenção dispensados à comunidade de entorno. ${ }^{3}$ Marcando a contradição entre o ocorrido e o que consta em documentos oficiais, está o operador argumentativo "porém", classificado por Neves (2000, p. 755) como "conjunção coordenativa", que, assim como o "mas", estabelece uma "relação de desigualdade" entre segmentos do enunciado, sendo utilizada para "a organização da informação e para a estruturação da argumentação", caracterizando uma "contraposição em direção oposta", pelo registro da morte não equivaler aos seus motivos de fato (a morte foi causada por desnutrição, "porém" tal causa não constará nos registros oficiais). A informação é organizada de forma que o leitor compreenda tal contradição e vem estruturar o argumento de que não constará como causa mortis a desnutrição.

3. Em revista, o processo identitário do indígena de Dourados (MS)

Cabe aqui situar o contexto em que a temática das reportagens em análise - a desnutrição infantil indígena - emergiu. Ela integra uma história que envolve o relacionamento entre duas culturas que, no Brasil, estiveram sempre interligadas: a cultura branca e a cultura indígena. Conflito que envolve questões vinculadas às relações de poder: pela terra, pelos costumes. Segundo Limberti (2009), na região do município de Dourados, ao sul do estado de Mato Grosso do Sul, essa relação se mostra por vezes bem demarcada: ela é ocupada por quase 200 mil habitantes, sendo mais de 11 mil indígenas, uma das maiores comunidades indígenas do Brasil. Há três aldeias: Panambizinho, Bororó e Jaguapirú, sendo estas duas últimas marcadas pela proximidade geográfica com a cidade de Dourados, o que estreita a relação entre índios e brancos que

\footnotetext{
${ }^{3}$ Idem à nota 25, sobre o artigo 54 do Estatuto do Índio.
} 


\section{Revista do SELL \\ v. $4, n^{\circ} .1$ \\ ISSN: $1983-3873$}

passam a compartilhar as discussões dos problemas enfrentados por ambos, especialmente mobilizadas pela ação dos jornais locais.

As aldeias Bororó e Jaguapiru compõem a conhecida Reserva Indígena de Dourados (RID), foco principal das discussões em torno dos casos de desnutrição infantil indígena. Ela é composta de uma população - mais de 10 mil - mista etnicamente, identificada como: Guarani, Kaiowá e Terena, além dos brancos, que ali são "integrados" pela união conjugal com os indígenas ou os que vivem no seu entorno, configurando uma rede de relações complexas que permite classificá-la como um "sistema multiétnico" (LIMBERTI, 2009). E foi diante desse contexto que um cenário de miséria e de morte começou a erigir de acordo com a progressão dos casos de desnutrição infantil indígena e da indicação dos possíveis culpados: os poderes públicos, a FUNAl, a FUNASA, os próprios indígenas - cenário esse visualizado, sobretudo, pelas lentes dos jornais locais, que imprimem em seus textos a constante "preocupação" em divulgar as várias versões, opiniões acerca do assunto. $O$ fato de a desnutrição não constar como a causa direta da morte de algumas crianças da Reserva interfere decisivamente nas estatísticas de mortalidade nas aldeias. No final do mês de fevereiro de 2005 , foram analisados os atestados de óbito para uma comparação com o ano anterior. Em matéria do dia 14 de março de 2005, a Folha On-line apresenta alguns dos dados referentes a essa análise, além de algumas porcentagens referentes a exames da FUNASA nas aldeias:

F4 - Funasa encontra 467 índios com problemas de nutrição em MS - Entre 2.236 crianças menores de cinco anos examinadas nas aldeias de Mato Grosso do Sul, a Funasa (Fundação Nacional de Saúde) informa ter encontrado 124 desnutridas (22 delas em estado grave) e 343 em risco nutricional (abaixo do peso normal). No total, são 467 crianças, ou 19,9\% com algum tipo de problema.

A Funasa começou, no fim de fevereiro, a fazer exame nas aldeias em ritmo de mutirão devido às mortes de crianças indígenas desnutridas. O órgão realizou uma análise em atestados de óbito e constatou que a desnutrição aparece como causa de 12 mortes neste ano. A informação foi repassada à Folha na semana passada. Em 2004, ocorreram 15 casos.

A matéria inicia com a afirmativa que a FUNASA "encontra" 467 índios com problemas relativos à desnutrição. O verbo "encontrar", de acordo com definição de Amora (2005, p. 342), significa "descobrir", "perceber". Levando-se em consideração que 


\section{Revista do SELL}

v. $4, n^{\circ} .1$

ISSN: $1983-3873$

o problema com a desnutrição nas aldeias já se estendia desde o ano de 2002 (AYLWIN, 2009, p. 54), a escolha do verbo "encontrar" traz efeitos de sentido que conferem distanciamento da FUNASA em relação ao problema. Partindo-se do pressuposto que todo "encontro" envolve uma "procura", cabe aqui refletir: teria a FUNASA demorado três anos para constatar que havia um problema sério de saúde a ser resolvido? As constatações da instituição estão expressas em F4 na forma de números e porcentagens, que se tornam questionáveis pelo fato de algumas mortes constarem no atestado de óbito como consequência de sintomas de desnutrição (diarreia, desidratação), e não pela desnutrição propriamente dita. O verbo "encontrar" está no presente do indicativo, o que caracteriza uma perspectiva de tempo relacional, uma vez que engloba eventos que aconteceram no passado e que possivelmente ocorrerão no futuro: pressupõe, pois, uma cadeia contínua de eventos (CORÔA, 2005, p. 26).

Os dados comparativos com relação ao ano de 2004 (no qual constam três mortes a mais) tornam-se inválidos mediante os "eufemismos" utilizados nos atestados de óbito: se fossem consideradas as mortes pela desnutrição - e não por seus sintomas -, os dados seriam estes? Quais os motivos para a desnutrição não constar como causa direta de algumas mortes? Estatísticas altas no número de mortes indicariam uma atuação medíocre da instituição, já que sua função é "enfrentar, através de diferentes estratégias tanto preventivas quanto curativas, a crítica realidade das condições de saúde existentes particularmente entre a população indígena da reserva”. (AYLWIN, 2009, p. 63). Consideramos, nesse aspecto, que o fato de a desnutrição não constar como causa principal de algumas mortes é uma forma de silenciamento, pois caracteriza algo que não foi dito - mas que é de conhecimento dos leitores e autoridades, de forma geral. As palavras que compõem o atestado em lugar de "desnutrição" materializam esse silêncio segundo Orlandi (2007, p. 11-12), “as próprias palavras transpiram silêncio" e, no caso dos atestados de óbito das crianças guaranis, pode-se afirmar também que "todo dizer é uma relação fundamental com o não-dizer": se as palavras que constam nos atestados são sintomas de desnutrição, isso indica que o motivo das mortes foi silenciado. A título de justificativa para algumas mortes que não teriam ocorrido por desnutrição, a FUNASA argumenta ainda sobre outro motivo de óbito.

Em parte da matéria de 14 de março, o Folha On-line reproduz a fala do diretor do departamento de saúde indígena da FUNASA a respeito de supostas mortes por infecção hospitalar: 


\section{Revista do SELL}

v. $4, n^{\circ} .1$

ISSN: $1983-3873$

F5 - Além do atendimento às crianças nas aldeias, a Funasa pediu à Prefeitura de Dourados (218 km de Campo Grande) que faça inspeção no hospital da Mulher, onde neste mês morreram três crianças indígenas, que não tinham desnutrição. Segundo Padilha [Alexandre Padilha, diretor do Departamento de Saúde Indígena da Funasa], a preocupação é com a infecção hospitalar.

O operador argumentativo "além de" introduz mais uma ação ao trabalho da FUNASA: o fato de responsabilizar-se pelo atendimento aos casos de desnutrição não a impedia de agir sobre outros casos, como a infecção hospitalar. Nesse caso, a FUNASA transferiu uma parte dessa responsabilidade para a Prefeitura de Dourados, solicitando uma inspeção do Hospital - e o efeito de sentido dessa atitude é o de que o Hospital não oferecia atendimento adequado aos pacientes. Isso ressignificava que a responsabilidade era política e social, ou seja, do Governo Municipal, além de mudar o foco da reportagem: da desnutrição para a infecção hospitalar.

Em matéria do dia 21 de março de 2005, a Folha On-line apresenta outros números relativos às mortes de crianças guaranis por desnutrição, e sua avaliação pelo então ministro da Saúde, Humberto Costa, a saber:

F6 - Desnutrição já matou 14 crianças indígenas em MS - A desnutrição matou ao menos 14 crianças indígenas, menores de cinco anos, da etnia guarani-caiuá em Mato Grosso do Sul neste ano. Durante 2004, foram 15 casos no Estado, segundo a Funasa (Fundação Nacional de Saúde), responsável pela assistência médica nas aldeias.

Essa estatística contraria avaliação feita no dia 8 de março passado pelo ministro Humberto Costa (Saúde). Ele disse, durante a reunião do CNS (Conselho Nacional de Saúde), em Brasília, que "as mortes estão dentro do número que normalmente acontece".

Na estatística de 14 mortes, a Funasa confirma 13. O outro óbito foi registrado na semana passada pela direção do Hospital Regional de Amambaí (393 km de Campo Grande), que é referência no atendimento de crianças indígenas no sul do Estado.

A matéria é iniciada pelo subtítulo "Desnutrição já matou 14 crianças indígenas em MS". De acordo com Neves (2000, p. 268), o termo "já", classificado pela autora como um advérbio de tempo, representa uma "situação relativa", por se referir "a um momento da enunciação ou do enunciado" - ou seja, até aquele momento em que o discurso do jornal 


\section{Revista do SELL}

v. $4, n^{\circ} .1$

ISSN: $1983-3873$

foi publicado, haviam morrido 14 crianças. As estatísticas apresentadas pela FUNASA não foram, no entanto, relevantes na opinião do ministro da Saúde Hélio Costa, que afirmou estarem as mortes "dentro do número que normalmente acontece", o que confere o efeito de sentido de que seria normal a morte de crianças por desnutrição em aldeias, mesmo havendo meios (e deveres institucionais) que visam a impedir tais óbitos ${ }^{4}$. Ao afirmar que o argumento do ministro contraria os dados fornecidos pela FUNASA, o jornal estabelece uma oposição entre a visão regional do problema (em que a FUNASA procura soluções, tanto para a situação de desnutrição nas aldeias quanto para salvar a própria imagem) e a visão nacional, representada na voz do ministro Hélio Costa, responsável por decisões referentes à saúde em âmbito nacional (que considera "normal" o número de mortes). Esse tipo de exposição gera polêmica na mídia - e expõe a sua característica de dualidade, que conjuga informação e certo "contrato de comunicação" com o público:

A máquina midiática é complexa [...] pela tensão permanente que existe entre as duas finalidades de informação e de captação de seu contrato de comunicação. Isto explica por que ela está marcada por um paradoxo: por um lado, pretende transmitir informação da maneira mais objetiva possível, e isso, em nome de valores cidadãos, por outro, só pode atingir a massa se dramatizar a cena da vida política e social. (CHARAUDEAU, 2009, p. 243)

Ao colocar a fala do ministro em oposição às afirmações da FUNASA, o jornal age como se afirmasse que "o ministro considera normal crianças indígenas morrendo por desnutrição", e isso atinge o público de forma significativa, interferindo em sua perspectiva social e política. Afinal, o poder que atua no País depende, em parte, do voto (e por vezes, do veto) dos cidadãos. Quanto à FUNASA, observa-se a persistência em classificar as mortes de forma a diminuir os números das estatísticas, contrariando o que afirma o jornal no título da notícia, "a FUNASA confirma 13 das 14 mortes divulgadas", deixando de fora de suas estatísticas a morte ocorrida em hospital da cidade de Amambaí. Portanto, fora da área "coberta" por sua pesquisa está também a Reserva Indígena de Dourados. Para salientar que o caso em questão não pertence à "sua" área, ainda é revelado que o óbito foi "registrado" na cidade de Amambaí, em que "registrar" pertence a uma formação discursiva jurídica - confere efeito de verdade à afirmativa pela

\footnotetext{
${ }^{4}$ Reafirmamos o papel da FUNASA quanto a "estratégias preventivas e curativas" (AYLWIN, 2009, p. 63) e ao Estatuto do Índio que decreta, no Art. 54: "Os índios têm direito aos meios de proteção à saúde facultados à comunhão nacional".
} 


\section{Revista do SELL}

v. $4, n^{\circ} .1$

ISSN: $1983-3873$

sua origem oficial, de um lugar de poder - e situa oficialmente a morte da criança como ocorrida na cidade de Amambaí.

Salientamos que o registro de fatos sob a forma jurídica deixa-os também impressos como registros históricos, constituindo uma "matéria inerte" da história do País (CUNHA, 1992, p. 101) - algo que permanece registrado e que traz fatos à memória. O registro da morte da criança guarani não constituirá o histórico da cidade de Dourados, ou da própria FUNASA; ficará restrito a um território "neutro", que não é exposto em pesquisas e nem associado a mortes e à desnutrição, sejam elas eventuais ou não - 0 que vem isentar a FUNASA e a Prefeitura de Dourados de sua ocorrência. Portanto, o que se observa pela análise empreendida é que o índio constitui uma espécie de "massa de manobra" dos políticos - um povo por meio do qual a classe política pode exercer seu poder e ainda aparecer na mídia devido aos efeitos de assistencialismo que a situação provoca.

Vale dizer ainda que Miqueletti (2007), da perspectiva da Semiótica, verificou que as imagens que parecem perpassar os jornais nacionais é a do indígena como vítima da situação de desnutrição, que sofre com o descaso do poder público, sujeito apresentado a partir de uma imagem negativa, e que precisa muitas vezes sair da sua condição de sujeito de estado para tentar fazer, transforma-se assim em "sujeito do fazer" que busca melhorias para si, para a comunidade. Para a autora, as pessoas vão "lendo" os indígenas e os demais sujeitos envolvidos nas notícias, por meio dos fios que tecem os textos nos jornais. Nessa esteira, para nós, os excertos problematizados trazem em seus (inter)discursos o olhar do colonizador, mobilizados, especialmente, pelos dizeres que se repetem com alguma regularidade e que trazem à tona imagens negativas dos índios ligados ao preconceito e aos estereótipos do passado. Parece-nos que a remanência dessas representações, a partir dos textos analisados, estabelece um dialogismo com outros textos, de forma a oferecer, por meio dessa interdiscursividade uma estabilidade no processo de significação: é uma imagem negativa, reproduzida por variadas vozes em condição de "complementaridade", desempenhando o importante papel de alimentar a memória histórica (LIMBERTI, 2009).

A seguir, trazemos as reflexões sobre os resultados desta pesquisa, que não pretendem ser exaustivas e permanentes em decorrência de sua perspectiva teórica e metodológica. 


\section{Revista do SELL}

v. $4, n^{\circ} .1$

ISSN: $1983-3873$

\section{4. $O$ que se mostra?}

Esta pesquisa visou a identificar as formas de representação social do índio no discurso midiático, e como essas imagens são construídas pelos múltiplos caminhos que se materializam na língua e compõem o discurso do jornal Folha-On-line. Diante desse objetivo, a análise dos excertos do jornal Folha On-line possibilitou que observássemos algumas regularidades em seus discursos, como certos verbos que marcam determinadas pessoas e os lugares em que elas atuam (autoridades e indígenas). Os excertos analisados utilizam estratégias de apresentação das notícias, dispondo-as sempre como manchetes principais, como algo que não pode simplesmente ser mencionado de forma superficial. Além disso, há o fator da espetacularização da notícia, que recebe todo tipo de ênfase com o intuito de impressionar, chamar a atenção dos leitores e aumentar os acessos às páginas de internet. Ao enunciarem sobre a desnutrição na Reserva Indígena de Dourados, os excertos frequentemente associam-na à morte, embora haja também poucos casos em que o problema surge resolvido. A repetição do tema, além de guardar em seu não-dito que há outras irregularidades ocorrendo - desvio de verbas, alimentos se deteriorando sem terem sido distribuídos -, visa não somente a reforçar essa situação, mas marcar a posição do indígena guarani na sociedade, e assim consegue manter essa imagem de "abandonado" - entre outras - perante os leitores.

Os excertos problematizados revelam em seus (inter)discursos uma perspectiva "colonial" de se ver o índio: permanece a visão do mesmo como um "coadjuvante" na História do País, baseada não em sua trajetória neste percurso, mas no imaginário de uma sociedade moldada pela História canônica. Colocadas sob a lente de aumento sensacionalista e espetacularizadora da mídia, tal imagem do índio é marcada, de forma quase definitiva no imaginário dos leitores, por meio de estratégias que conferem efeitos de verdade aos enunciados. Os efeitos de verdade alcançados pelos enunciados dos jornais são enfatizados pela presença de diversas formações discursivas que apoiam seus discursos e conferem-Ihes a credibilidade necessária para seduzir o público. Assim, as formações discursivas médicas, jurídicas, institucionais e políticas, identificadas nos excertos analisados, marcam o lugar de poder daqueles que proferem os discursos e dão força às representações ali marcadas, e que se perpetuam no imaginário popular e na memória discursiva do público - que irá associar a figura do índio à imagem vendida e construída pelo jornal. 


\section{Revista do SELL \\ v. $4, n^{\circ} .1$}

ISSN: $1983-3873$

Ao analisar os enunciados da Folha On-line, confirmamos nossa hipótese de que as notícias constroem representações do índio no imaginário dos leitores, e de que a relação entre índio e branco é permeada de "tensões", que são a raiz da maioria dos conflitos apresentados na análise de dados. E, a partir das reflexões apresentadas, pudemos trazer algumas das representações encontradas durante o processo de problematização dos enunciados. Nessa direção, é válido ressaltar que não pretendemos preencher todas as lacunas referentes à representatividade do índio guarani pela mídia: certamente, há muitas outras imagens a serem exploradas, mas apresentamos aqui as mais relevantes e regulares nos discursos dos suportes midiáticos em análise, numa contribuição à pesquisa sob o prisma da Análise do Discurso de linha francesa numa interlocução com a perspectiva culturalista.

A representação do índio guarani como "marginal" está presente no discurso dos enunciados. Não empregamos aqui a palavra "marginal" no sentido de "bandido' ou "contraventor", como comumente é empregado, mas sim no sentido de indivíduo que vive à margem da sociedade, no que se pode considerar como periferia. Nos excertos mencionados, a escolha vocabular para referenciar o índio guarani o qualifica como "nômade", "coletor" - uma comparação com os moradores de rua -, desnutridos, viciados e dependentes do assistencialismo do governo. Permanece a estratégia de utilizar discursos provenientes de formações discursivas institucionais e políticas para a manutenção dessa imagem, ao ser construída por meio do discurso de autoridades.

Identificamos, também, no discurso jornalístico a representação do índio como "incapaz". Tal representação se constitui a partir de como determinadas situações são apresentadas ao leitor: a índia cujo filho "morreu de fome" e ela nada pôde fazer para impedir; a mesma mãe declarando não ter alimentos para os filhos; os pais que tiram a criança do hospital, mas não conseguem impedir sua morte; os índios dependendo de "sopão comunitário" para se alimentarem - todas as situações mencionadas colaboram para a fixação da imagem do índio guarani como incapaz de se sustentar. Aliado à estratégia do uso de discursos de formações discursivas médicas e políticas, está o recurso da repetição, que também colabora para a manutenção de tal imagem na memória discursiva do leitor.

Diante do apresentado acerca dos excertos retirados da Folha On-line, chegamos à conclusão de que o índio é representado como um indivíduo que não possui espaço para seu argumento; e, quando esse espaço surge, se apresenta na forma de discursos indiretos e com grande interferência do discurso jornalístico - que por sua vez carrega em 


\section{Revista do SELL}

v. $4, n^{\circ} .1$

ISSN: $1983-3873$

si os discursos institucionais e políticos que conferem valor de verdade ao que é publicado. Portanto, quem assume o direito de argumentar sobre os índios guaranis são as entidades que se autointitulam responsáveis por eles, do alto de seus lugares de poder. Por outro lado, aqueles que se pronunciam a respeito da comunidade indígena por meio da mídia tiram o direito dos índios de se manifestarem e organizarem seus discursos na imprensa, de forma a se constituírem como sujeitos ativos e exporem seus discursos.

Por mais que as condições de marginalidade e de "figuração" do índio sejam históricas (desde a época do "descobrimento", convencionou-se atribuir o poder a outros "protagonistas"), ainda na atualidade ela é alvo de uma exploração que obedece a conveniências várias: ora pode aumentar a venda de jornais, ora pode demonstrar sua dependência frente a um sistema político e institucional que, em lugar de apoiá-lo e incluílo em uma sociedade que para ele é "estranha", o expõe ainda mais em sua fragilidade. Nesse contexto, as imagens do índio guarani atendem aos apelos sensacionalistas, sendo espetacularizado pelo jornal Folha On-line, que os representam como abandonados, subalternos, miseráveis, selvagens, submissos, vítimas, marginais, incapazes. Afirmamos, sem medo de errar, que o espaço midiático reproduz as mesmas relações predominantes na sociedade que, por sua vez, se fundamenta na própria História que, em seu descontínuo percurso, construiu imagens equivocadas do índio, representações perpetuadas pelos diversos discursos que carregam em si marcas históricas, culturais e sociais.

Por fim, esperamos ter mostrado, da perspectiva discursiva e culturalista, que a mídia constrói todo um universo discursivo, em torno dos problemas da etnia guarani de Dourados (MS), a partir de discursos que chegaram até a contemporaneidade por um trabalho de memória de interdiscurso, resultados de um complexo de ideologias presentes em conjuntos de práticas discursivas diversas. Observamos, ainda, que o lugar de produção dos discursos analisados, longe de ser pacífico, é um campo fecundo, ativo, de lutas pelo poder, sucessivas disputas e batalhas discursivas.

\section{Referências}

AMORA, Antônio S. Minidicionário Soares Amora da língua portuguesa. 12. ed. São Paulo: Saraiva, 2003.

AUTHIER-RÉVUZ, Jacqueline. Heterogeneidade(s) enunciativa(s). Trad. Celene M. Cruz e João W. Geraldi. Cadernos de Estudos Lingüísticos, №. 19. Campinas: Editora da UNICAMP, 1990, p. 311-319. 


\section{Revista do SELL \\ v. $4, n^{\circ} .1$}

ISSN: $1983-3873$

AYLWIN, José. Os direitos dos povos indígenas em Mato Grosso do Sul, Brasil: confinamento e tutela no século XXI. Trad. Maria Regina Toledo Sader. São Paulo: IWGIA; FMUSP, 2009.

BHABHA, Homi. O local da cultura. Trad. Myriam Ávila, Eliana L. de Lima Reis, Gláucia R. Gonçalves. Belo Horizonte: UFMG, 1998.

BRANDÃO, Carlos R. Identidade e etnia: construção da pessoa e resistência cultural. São Paulo: Brasiliense, 1986.

BRASIL. Constituição (1988). Constituição da República Federativa do Brasil. Brasília: Senado Federal, secretaria- Geral da Mesa, 2003. 221 p.

CASTELLS, Manuel. Paraísos comunais: identidade e significado da sociedade em rede. In: _ . O poder da identidade. Trad. Klauss B. Gerhardt. São Paulo: Paz e Terra, 1999, p. 21-28.

CHARAUDEAU, Patrick. Discurso das mídias. Trad. Angela S. M. Corrêa. São Paulo: Contexto, 2009.

CHARAUDEAU; Patrick, MAINGUENEAU, Dominique. Dicionário de Análise do Discurso. Trad. Fabiana Komesu. São Paulo: Contexto, 2004.

CORACINI, Maria J. F. R. A celebração do outro: arquivo, memória e identidade. Campinas: Mercado de Letras, 2007.

CORÔA, Maria L. M. S. O tempo nos verbos do português. São Paulo: Parábola, 2005.

CUNHA, Manuela C. da. Introdução a uma história indígena. In: . (org.). História dos índios no Brasil. 2. ed. São Paulo: Companhia das Letras: 1992, p. 9-24.

ESTATUTO DO ÍNDIO, Lei n.ำ 6.001, de 19 de dezembro de 1973.

FIORIN, José L. As astúcias da enunciação: as categorias de pessoa, espaço e tempo. São Paulo: Ática, 1996.

FLORES, Valdir do N. et al. Enunciação e gramática. São Paulo: Contexto, 2008.

FOLHA ON-LINE. Disponível em: <http://www1.folha.uol.com.br> Acesso em: 24/ $011 / 2012$ às $14 \mathrm{~h} 33 \mathrm{~min}$.

FOUCAULT, Michel. A ordem do discurso. 3. ed. Trad. Laura Fraga de Almeida Sampaio. São Paulo: Loyola, 1996.

Method. In: . The history of sexuality: an introduction. V1, Vintage, 1990. p. $92-102$

LIMBERTI, Rita C. P. Discurso indígena: aculturação e polifonia. Dourados: Editora UFGD, 2009.

MIQUELETTI, Eliane A. Desnutrição infantil indígena em foco: análise de uma reportagem de jornal. ANAIS DO III CELLMS, IV EPGL e I EPPGL - Universidade Estadual de Mato Grosso do Sul/Dourados. 08 a 10 de outubro de 2007. 


\section{Revista do SELL}

v. $4, n^{\circ} .1$

ISSN: $1983-3873$

NEVES, Maria H. de M. Gramática de usos do português. São Paulo: UNESP, 2000.

ORLANDI, Eni P. As formas do silêncio: no movimento dos sentidos. 6. ed. Campinas: Editora Unicamp, 2007.

PERINI, Mário A. Gramática do português brasileiro. São Paulo: Parábola, 2010.

RAMOS, Alcida R. Sociedades indígenas. 2. ed. São Paulo: Ática, 1988.

RONCARATI, Cláudia. As cadeias do texto: construindo sentidos. São Paulo: Parábola Editorial, 2010.

SILVA, Alena C. As expressões referenciais como marcadores de alternância no discurso literário. In: CAVALCANTE, Mônica Magalhães, et al (orgs.). Texto e discurso sob múltiplos olhares: referenciação e outros domínios discursivos. Rio de Janeiro: Lucerna, 2007, p. 195-219.

SOUZA, Jessé. A singularidade da "nova periferia". In: A construção social da subcidadania: para uma sociologia política da modernidade periférica. Belo Horizonte: Editora UFMG; Rio de Janeiro: IUPERJ, 2003, p. 93-149. 